\title{
Invisibilidade, superficialidade e plasticidade: três hipóteses sobre as câmeras inteligentes
}

\author{
Icaro Ferraz Vidal Junior
}

Resumo: O presente artigo propõe três hipóteses concernentes às câmeras inteligentes: 1) que há uma tendência dos diagramas que se inscrevem algoritmicamente na superfície da imagem a se invisibilizarem; 2) que a ênfase na superficialidade das condutas vincula-se ao deslocamento para superfície dos corpos do locus privilegiado de subjetivação a partir da segunda metade do século XX e a uma ênfase contemporânea na ação; 3) que o caráter preditivo e antecipador dos dispositivos inteligentes de visibilidade é um sinalizador importante de uma crise contemporânea aqui formulada como uma crise da plasticidade e do hábito.

Palavras-chave: câmeras inteligentes; tecnologias digitais; plasticidade.

Abstract: Invisibility, Superficiality and Plasticity: Three Hypotheses on Smart Cameras - This paper proposes three hypotheses concerning the smart cameras: 1) there is a tendency of the algorithmically inscribed diagrams on the surface of the image in order to make themselves invisible; 2 ) the emphasis on superficiality of conducts is linked to the replacement of the privileged locus of subjectivity towards the surface of the bodies in the second half of the twentieth century and to a contemporary emphasis on action; 3 ) the predictive and anticipatory nature of intelligent devices of visibility is an important indicator of a contemporary crisis here formulated as a crisis of plasticity and habit.

Keywords: smart cameras; digital technologies; plasticity.

\section{Introdução}

Em 2010, o portal Engadget anunciava que em breve os passageiros de táxi em Tóquio não precisariam preocupar-se com o risco de esquecerem seus pertences a bordo. Câmeras instaladas sob os bancos dianteiros, no teto e no porta-malas das viaturas da empresa Kokusai Motorcars Co. passariam a operar a partir da convergência entre tecnologias digitais de produção de imagens e softwares que, em tempo real, poderiam empreender 
uma leitura da imagem produzida. Com o monitoramento das áreas destinadas aos passageirose às cargas, passaria a ser possível reconhecer imediatamente, no momento da saída de um passageiro, a presença de algo que não estava lá quando de sua entrada. Diante de tal reconhecimento, soaria um alarme e o passageiro não precisaria mais iniciar um périplo pela recuperação de seu celular ou de sua carteira após a partida do táxi (SEPPALA, 2013). A notícia termina por sublinhar o baixo custo deste sistema, que há pouco tempo provavelmente estaria nas páginas de ficção científica.

Este relato de uma potencialmente corriqueira utilização de câmeras inteligentes conjugado no futuro do pretérito deve-se, por um lado, à ausência de informações a respeito da efetiva implementação deste dispositivo no site da empresa de táxi ${ }^{1}$, mas, por outro, ao estatuto que atribuiremos ao aparato técnico a partir de algumas ideias de Fernanda Bruno (2012). Bruno apresenta um mapeamento preliminar do ingresso das câmeras inteligentes nos sistemas de videovigilância e traça algumas considerações metodológicas de partida, que nos interessa retomar, sobretudo a ideia de programa de uma tecnologia.

Derivada das teses de Michel Foucault (1997) e Jonathan Crary (1992), a ideia de que determinados aparelhos funcionam como emblemas de formações históricas, culturais e epistemológicas torna-se problemática no que diz respeito às câmeras inteligentes. Três aspectos fazem com que isso aconteça: o fato de que emblematizam mais o ideal de uma lógica do que um estado de coisas já cristalizado; a atual situação destes dispositivos, que estão em vias de difusão e, portanto, "entre o presente e o futuro próximo" e; sua prometida eficácia, frequentemente ancorada na denegação de sua ineficácia ou impossibilidade (BRUNO, 2012, p. 49). Estes aspectos, no entanto, indicam uma condição privilegiada do dispositivo no sentido de permitir a visualização de disputas e controvérsias que se encontram arrefecidas nos emblemas bem-acabados. Neste sentido, mimetizaremos o gesto de Bruno ao nos determos no programa desta tecnologia, "isto é, aquilo que as suas redes de produção promovem como suas 'qualidades'” (ibid.), acompanhando a autora também na atenção "às suas ambiguidades, brechas, disfunções, bem como às suas tensões com outras redes que constituem o diagrama em que este programa se atualiza" (ibid.).

O programa dos dispositivos de videovigilância inteligente é abordado por Bruno em três planos: por suas ordenações do visível; pelo foco em uma dimensão superficial das condutas; e pelos regimes de temporalidade do aparelho, que opera uma redução do intervalo entre visão e ação, ao mesmo tempo em que é capaz de produzir uma memória preditiva (ibid.). Estes planos fundamentam as hipóteses que aqui formularemos: 1) que se esta nova ordenação do visível é crucial no desenvolvimento da terceira geração de videovigilância, a difusão das câmeras inteligentes em contextos mais amistosos, como é o caso dos táxis japoneses, tende a tornar invisíveis os diagramas que algoritmicamente se inscrevem na superfície da imagem; 2) que a ênfase na superficialidade das condutas vincula-se tanto ao deslocamento para a superfície dos corpos do locus privilegiado

1 Disponível em: <https://www.km-group.co.jp/en/about/>. Acessado em 13 ago. 2015. 
de subjetivação, quanto ao declínio da interioridade nas formulações teóricas psi desde a segunda metade do século XX e a uma ênfase contemporânea na ação; 3) que o caráter preditivo e antecipador dos dispositivos inteligentes de visibilidade é um sinalizador importante de uma crise contemporânea aqui formulada como uma crise da plasticidade e do hábito, ou segunda natureza (MALABOU, 2005).

\section{Reordenações do (in)visível}

A reordenação do visível nos sistemas de videovigilância inteligente vem responder a limitações que a percepção e a atenção humanas apresentam ao ideal de controle total dos contextos vigiados. As tentativas de driblar esta dimensão flutuante da atenção encontram-se na própria transformação da atenção em problema pelo campo da psicologia na primeira metade do século XX. Com o acontecer da Segunda Guerra Mundial, observou-se uma série de problemas com os controladores de radar. Os longos períodos de exposição e espera diante de imagens que, mesmo na ausência de eventos atrativos, demandavam um elevado engajamento atencional, colocavam um problema de ordem prática às forças armadas, que contaram com o suporte das então reemergentes abordagens da psicologia da atenção (GÓMEZ-IÑIGUEZ et al., 1999). As câmeras inteligentes operam como filtros que oferecem imagens interpretadas segundo algoritmos que sublinham desvios de padrões, dando destaque àquilo que seria digno da atenção do vigilante.

Um exemplo desta reordenação do visível pode ser encontrado no sistema Tag and Track, desenvolvido por pesquisadores da Universidade Kingston de Londres e eleito sistema de circuito fechado de televisão do ano de 2012 na Exposição e Conferência Internacional de Fogo e Segurança (IFSEC). De acordo com Sergio Velastin (2012), especialista em visão computacional aplicada na referida universidade, "o sistema baseia-se em duas coisas primeiramente, na identificação de uma pessoa através de características, tais como sua aparência, que diferentes câmeras podem capturar. Em segundo lugar, tem a capacidade de parar as buscas das câmeras por estas características em uma área desnecessariamente grande $^{\prime 2}$. James Orwell (2012), o pesquisador que coordenou a equipe que deu início ao desenvolvimento do sistema, explicou seu funcionamento nos seguintes termos:

\section{Uma vez que os operadores notam um comportamento potencialmente suspeito, eles podem marcar a pessoa em questão, clicando sobre a sua imagem (...) Isso aciona o sistema para voltar ao banco de dados e imediatamente criar uma rota completa para a pessoa em questão, usando dados armazenados. A tecnologia pode fornecer previsões sobre os passos dos indivíduos de antemão, bem como descobrir para onde eles vão depois. ${ }^{3}$}

2 Disponível em: <http://www.kingston.ac.uk/news/article/609/22-jun-2012-cuttingedge-advance-in-cctv-softwareearns-industry-acclaim/>. Acessado em 19 fev. 2015. Todas as traduções são nossas.

3 Disponível em: <http://www.kingston.ac.uk/news/article/609/22-jun-2012-cuttingedge-advance-in-cctv-softwareearns-industry-acclaim/>. Acessado em 19 fev. 2015. 
Os três âmbitos do programa dos dispositivos de videovigilância inteligentes apontados por Fernanda Bruno (2012) podem ser claramente vislumbrados nas descrições de Tag and Track. Se o regime de visibilidade agenciado pelas imagens de videovigilância inteligente orienta nossa atenção e organiza nossa percepção, é importante desdobrar a diferença entre tais dispositivos e os dispositivos nos quais as imagens servem a certas operações, prescindindo do olhar humano, como é o caso, por exemplo, do robô de Hans Moravec (BELBACHIR; GÖBEL, 2010, p. 9-10) e, mais recentemente, de alguns processos de automação no âmbito industrial, bem como de experiências mais triviais, como a da empresa de táxi japonesa.

Poderíamos identificar na rede sociotécnica da videovigilância a necessidade de conexões entre atores humanos e atores não-humanos em virtude de uma irredutibilidade deste contexto - atravessado pelo direito e pelas políticas públicas - a sua dimensão tecnológica. O valor desta especulação associa-se ao fato de que a questão crucial para o avanço na formulação de nossa hipótese consiste em saber se o programa das câmeras inteligentes tende a privilegiar a exibição de imagens diagramadas, de modo a orientar nossa percepção e atenção, como é o caso da videovigilância inteligente; ou se a realização total de seu ideal consistiria na colocação de imagens tecnologicamente mediadas no interior de uma caixa preta.

A noção de imagem operativa, tal como formulada por Harun Farocki (2004, p. 17), ajuda-nos a compreender alguns deslocamentos importantes nos regimes contemporâneos de visibilidade: "Eu chamo tais imagens, feitas não para entreterem nem para informarem, 'imagens operativas'. Essas são imagens que não representam um objeto, mas antes são parte de uma operação." Farocki atribui seu interesse por tais imagens a um possível desgaste das imagens não-operativas e da metalinguagem. As imagens da indústria do cinema e da televisão não provêm, escreve o artista, nem do micro, nem do macrocosmo, mas de um nível intermediário cujas fronteiras vão de um close-up do rosto até o quarteirão de uma cidade. Trata-se do recheio de um sanduíche cósmico que, na sua abundância contemporânea, alteraria a lógica de sublimação do desejo que marca, no desdobramento desta metáfora, a interdição à criança de comer apenas o recheio do sanduíche. O que nos interessa aqui é a ideia de que o ecossistema de imagens que relega a visibilidade das imagens operativas a âmbitos restritos, como o da videovigilância e o militar, inclui um cenário mais abrangente e tem como revés a superprodução de imagens midiáticas.

Sobre a famosa exposição ctrl[space]: Rhetorics of Surveillance from Bentham to Big Brother realizada em 2001, Farocki (ibidem) destaca que seu foco eram imagens que não estavam enquadradas de modo a comprimir espaço e tempo. Seu interesse eram filmes e fotografias produzidos para monitorar processos que não seriam passíveis de observação pelo olho humano. O contra-uso que Farocki (ibidem, p. 18) dá a tais imagens atrela-se a seu interesse por uma beleza não calculada, não intencional e não autoral e à constatação de que 
"o comando militar dos Estados Unidos ultrapassou todos nós na arte de mostrar alguma coisa que chega perto do 'inconsciente visível'". Esta ideia de um inconsciente visível (manifesto parcialmente nas imagens operativas) interessa na medida em que esta primeira hipótese de uma tendência à invisibilidade das imagens operativas implicaria o apagamento dos diagramas que inconscientemente orientam nosso olhar.

Assim, a reorganização do visível levada a cabo pelas câmeras inteligentes em função de expectativas pré-estabelecidas de percepção e atenção inscreve-se em uma zona de tensão marcada, por um lado, pela diagramação em tempo real, através de softwares de video tracking e video analytics, de imagens que se mostram para vigilantes, soldados, médicos, etc. Por outro lado, a partir da lembrança de Harun Farocki (ibidem) de que Paul Virilio detectara no programa das imagens inteligentes utilizadas em contextos de guerra uma intenção em fazer crer que tais imagens eram profecias autorrealizáveis, podemos especular que a agência humana no interior de tais redes tende a ficar restrita à programação de softwares que, a partir de sua instalação, passam a operar automaticamente, mas não cegamente.

\section{Imagem, corpo, ação}

O segundo traço que Fernanda Bruno aponta como característico nos dispositivos inteligentes de videovigilância é sua ênfase em uma dimensão superficial das condutas, o que parece ser um deslocamento contemporâneo da moderna ênfase na interioridade, mas também o resultado epistemológico e o motor da própria emergência e proliferação das câmeras inteligentes. Ou seja, há toda uma história da topologia das subjetividades que vem sendo escrita por autores como Foucault (1988, 1997, 2006), Bezerra (2002), Sennett (1999), Sibilia (2008) e Bruno (2013) e esse deslocamento encontra-se profundamente amalgamado a certos dispositivos técnicos. Em História da sexualidade I: a vontade de saber, Vigiar e punir e $O$ nascimento da clínica, Michel Foucault, embora perscrutando âmbitos distintos da formação histórica moderna, chega a um ponto de contato entre os domínios da sexualidade, da punição e da clínica: uma distribuição do visível que, ao estabelecer o visível e o enunciável sobre a superfície aparente do mundo, forja um sujeito cuja verdade encontra-se interioriorizada, chegando a prescindir de ações que, eventualmente, poderiam ir na contramão desta aparência.

A tópica que contemporaneamente organiza as subjetividades parece ter sofrido um deslocamento desta interioridade opaca que fora analogicamente investida pelas instituições modernas. Tal deslocamento teria realocado a subjetividade na superfície dos corpos, digitalmente espelhada em uma série de interfaces - que vão das redes sociais até as novas tecnologias de diagnóstico por imagem, passando pelas atuais tecnologias de segurança - que, através da inscrição dos sujeitos em superfícies pixeladas, estabelece uma nova economia do visível e do enunciável. Adjacente a este cenário, testemunhamos as mutações nos regimes psi de elaboração de si, com uma ênfase progressiva, a partir 
dos anos 60, na dimensão comportamental e um crescente compromisso com as noções de eficácia e performance que, após migrarem do universo esportivo para o âmbito empresarial, espraiam-se por todo o tecido social (EHRENBERG, 1991).

Não interessa aqui retomar detidamente o conjunto de cada uma destas transformações que tangenciam a ênfase das câmeras inteligentes na superficialidade das condutas. A alusão a tais mutações não tem outro sentido senão o de indicar uma rede complexa que reintroduz a ação como alvo dos regimes de visibilidade, em detrimento de uma verdade íntima do ser, que seria anterior a qualquer ação. A superficialidade da ação é inserida nos ordenamentos contemporâneos do visível, deslocando o sentido de práticas similares, de catalogação e arquivamento de padrões corporais modernos (como os quadros de Alphonse Bertillon), como Fernanda Bruno (2012, p. 57) observa:

\footnotetext{
Nas tipologias de que estamos tratando [a videovigilância inteligente] [...] não se trata mais de diagnosticar uma personalidade criminosa sob a imagem e os detalhes corporais, mas de antever, na superfície da imagem e nos movimentos dos corpos, um possível crime ou incidente por vir.

As diferenças entre estes modelos indiciários e suas respectivas temporalidades estão atreladas ao caráter proativo da videovigilância inteligente.
}

A citação acima encaminha o aspecto da temporalidade que opera em tais dispositivos e nos permite formular, a partir das teses de Richard Sennett (1999), um estatuto controverso para as ações monitoradas por tais dispositivos. Em O declínio do homem público, Sennett desenha o cenário da modernidade como tendo abrigado uma série de práticas que produziram um inchaço do espaço privado através de uma valorização moral da autenticidade dos sujeitos em detrimento das máscaras sociais, que são condição da vida pública/política. O privilégio conferido a esta noção de autenticidade teria promovido uma avalanche de discursos confessionais acerca do que se era no espaço da intimidade e colocado a ação pública em uma zona sombria sob a desqualificação de falsamente motivada. Tomar parte na vida pública é algo que, em sua forma fundamental, vincula-se à ação política, uma ação que se destaca de intenções íntimas e tem como horizonte o futuro da comunidade.

A escolha do tipo de ação a ser monitorada pelos dispositivos inteligentes de visibilidade é de ordem política, mas o modo através do qual tal investimento se dá coloca de modo problemático a questão do futuro a que se direciona uma ação. O que confere esta dimensão problemática à ação monitorada no que ela potencialmente articula entre futuro e política tem a ver com uma centralização econômico-institucional do processo de padronização e antecipação das ações, que acaba por instaurar uma desigualdade entre os regimes temporais daqueles que agem em nome da preservação de uma certa lógica e daqueles que agem de modo a indicar (e potencializar) suas fraturas. Assim, a antecipação torna-se um privilégio tecnicamente obtido e a serviço da realização 
de um futuro previamente desenhado. Este controle técnico e centralizado sobre acasos e desvios é a colonização do futuro.

\title{
Plasticidade delegada
}

A mutação no regime de temporalidade agenciado por tais dispositivos é o terceiro plano de análise descrito por Fernanda Bruno (2012). A temporalidade propagada pelas descrições dos desenvolvedores de câmeras inteligentes é a do tempo real. Mas já não se trata mais de uma imagem que é formada simultaneamente àquilo que acontece diante da câmera, como em qualquer sistema de transmissão ao vivo. De acordo com Bruno (ibidem, 2012, p. 57-58),

\begin{abstract}
[...] além da transmissão e observação em tempo real, já presentes na videovigilância controlada por operadores humanos, os sistemas inteligentes efetuariam uma análise automatizada e "instantânea" da cena vigiada, permitindo que qualquer intervenção se dê no momento mesmo do instante flagrado. Suprimem-se, em tese, possíveis delays ou retardos, seja da percepção e atenção humanas, seja da ação no momento oportuno. O tempo real almejado aqui não é o da observação, da detecção ou da ação tomados isoladamente, mas o da conexão quase que imediata entre esses três "momentos" diacrônicos, diminuindo ao máximo o intervalo entre eles.
\end{abstract}

O desenvolvimento das tecnologias de processamento de dados no campo visual coloca em operação nestas câmeras uma memória cujo estatuto excede aquele do registro e arquivamento das imagens. Trata-se, agora, de uma memória capaz de se servir utilmente de todos os dados armazenados e inapreensíveis como conjunto em escala humana. O estatuto paradoxal de um incerto índice do porvir é formulado por Bruno (ibidem) a partir de Barthes (2006), para quem "o índice do passado tem a relativa estabilidade do 'isso foi' e o índice do presente tem a suposta referencialidade viva do 'isso é' ou 'está sendo', o índice do porvir é por natureza incerto e, neste caso, inverificável, uma vez que o caráter proativo deve conjurar aquilo que ele indica que está por vir". Aqui, cremos que as articulações entre a temporalidade instaurada pelo hábito e a noção de plasticidade, formuladas, a partir da filosofia de Hegel, por Catherine Malabou (2005), podem auxiliar no diagnóstico do que este incremento técnico coloca em jogo com respeito ao nosso momento histórico.

A partir de The future of Hegel: plasticity, temporality, dialectic, de Catherine Malabou (ibidem), iremos reivindicar certas tendências político-filosóficas como subjacentes a esta orientação do regime de temporalidade que investe tecnicamente sobre o futuro, de modo a lhe dar uma forma previamente estabelecida. Toda especulação de Malabou na primeira parte deste livro consiste em colocar a questão do futuro no interior da filosofia de Hegel. Nosso gesto, nos próximos parágrafos, irá buscar, nas potentes noções de plasticidade e de hábito, uma via para a recolocação do problema da articulação entre tempo e política no caso das câmeras inteligentes. 
A filósofa encara a noção de plasticidade no interior da filosofia de Hegel como "a 'instância' que dá forma ao futuro e ao tempo" (idem, p. 5). Neste sentido, tempo e futuro aparecem como "envolvidos mutuamente em um processo dialógico governado pela plasticidade". No mapeamento dos sentidos atribuídos ao termo ordinário plasticidade, as duas atribuições correntes do adjetivo plástico são: "por um lado, ser 'suscetível a mudanças de forma' [...]; e por outro lado, 'ter o poder de conferir forma, o poder de moldar'" (idem, p. 8).

O primeiro lugar de ocorrência da noção de plasticidade no pensamento de Hegel é em sua Estética, onde a escultura é concebida como a arte plástica por excelência. Mas o sentido da plasticidade será complexificado quando o filósofo formular a noção de individualidades plásticas para designar alguns gregos antigos, por ele considerados exemplares. "Eles são grandes e livres, crescidos independentemente sobre o solo inerente de sua própria personalidade, autorrealizados, e se desenvolvendo naquilo que eles (essencialmente) foram ou quiseram ser" (HEGEL, 1975 apud MALABOU, 2005, p. 9). As individualidades plásticas, conclui Malabou, dão forma ao espiritual em sua incorporação. Esta atividade-de-forma é pensada como a relação entre substancialidade e acidentalidade.

A articulação entre temporalidade, plasticidade e dialética culmina em uma estrutura antecipatória, interior à própria subjetividade, tal como concebida por Hegel. Averiguar o que repercute desta estrutura no programa das câmeras inteligentes pode nos encaminhar a uma compreensão da emergência e proliferação de tais dispositivos à luz da noção de hábito.

Para distinguir esta estrutura do futuro, tal como ele é entendido, vamos chamar esta estrutura 'ver (o que é) que vem' (le 'voir venir'), obedecendo a injunção de Hegel de filosofar no próprio idioma. 'Voir venir' em francês significa esperar, embora, como é prudente, observando como os eventos estão se desenvolvendo. Mas também sugere que as intenções e os planos das outras pessoas devem ser sondados e imaginados. É uma expressão que pode, portanto, referir-se ao mesmo tempo ao estado de 'estar certo do que vem' ('être sûr de ce qui vient') e de 'não saber o que vai vir' ('ne pas savoir ce qui va venir'). É por esse motivo que o 'voir venir', 'ver (o que é) que vem', pode representar aquela ação recíproca, dentro da filosofia hegeliana, de necessidade teleológica e surpresa. (idem, p. 13).

A estrutura antecipatória no pensamento de Hegel não é a-histórica. Malabou (ibidem) assinala dois momentos fundamentais do advento da subjetividade: o grego, que operava segundo uma lógica do sujeito como substância; e o moderno, organizado segundo a lógica inversa da substância como sujeito. O que Hegel faz é investigar, sob uma perspectiva filosófica, estes dois modos de operação que se sucederam na história e cujas formulações seminais são atribuídas, respectivamente, a Aristóteles e a Kant.

Nossa primeira intuição aqui demanda um redimensionamento das partes em jogo no esquema hegeliano: necessidade teleológica e surpresa. O programa das câmeras inteligentes parece sintomatizar um crescimento de necessidade teleológica e 
uma correspondente desqualificação da surpresa, como devendo ser banida da experiência temporal tecnologicamente mediada, ou prevista e interceptada antes de sua concreção. Esta estrutura de antecipação - marcada pela imaginação e sondagem dos planos e intenções dos outros e por estar certo do que está vindo e não saber o que está vindo sofre uma clivagem, de modo que a realização ideal das expectativas que se inscrevem na propagação das câmeras inteligentes implicaria o banimento do segundo polo dos pares acima: tanto a verificação das intenções e planos do outro, quanto não saber o que está vindo são banidos, respectivamente, pela ação antecipatória e pela subscrição do que está vindo em um sistema algorítmico de cálculos e intervenções, marcadas pelo privilégio da teleologia em detrimento da surpresa.

Elemento central na constituição destas estruturas antecipatórias é o hábito, que aparece no interior do processo dialético através do qual Hegel faz a passagem da Filosofia da natureza à Filosofia do espírito. O final da Filosofia da natureza, sobre a alma e suas funções, é também o início da Filosofia do espírito. Às questões que a alma, como fronteira partilhada entre natureza e espírito, coloca, Malabou (ibidem, p. 26) esboçará uma resposta, crucial para entendermos o conceito de hábito:

[...] a transição da natureza ao espírito não ocorre como uma superação, mas como uma reduplicação, um processo através do qual o espírito constitui a si mesmo em e como uma segunda natureza. Esta reduplicação reflexiva é em um certo sentido a 'fase do espelho' do espírito, na qual a primeira forma de sua identidade é constituída. O homem aparece como o avesso do animal, não como seu oposto. O conceito de 'segunda natureza', sinônimo de hábito, nos permite iluminar a grande originalidade da Antropologia.

Assim, o self antropológico pode ser compreendido como o resultado de um processo dialético de automodelação conjunta de corpo e alma, mediado pelos esforços do hábito. A consistência de que o self é dotado para ver (o que é) que vem, ou seja, o que lhe permite ligar-se ao futuro é, em Hegel, atribuída ao hábito. A ideia do hábito como segunda natureza tem a ver com o fato de que ele opera substituindo uma imediação natural por uma segunda imediação, colocada pelo espírito através desta espécie de memória.

A filósofa apresenta o trabalho do hábito, citando Hegel, como consistindo em "integração e modelagem da corporalidade que ingressa nos modos de sentir como tal e nas determinações de representação e vontade na medida em que elas tomaram formas corporais" (HEGEL, 1971 apud MALABOU, 2005, p. 38). A repetição transforma o aspecto corporal e a prática cria o hábito, cuja operação plástica resulta na transformação do corpo em instrumento. A transformação na temporalidade promovida pelo hábito é formulada nos seguintes termos:

Essa interpenetrabilidade do psíquico e do físico tem consequências imediatas para o tempo. Quando a natureza passa sobre a segunda natureza, isso implica, 
pela mesma razão, que 'tempo natural' - a simples exterioridade de momentos ligados uns aos outros como se numa sequência linear pura - é interiorizado e adquire uma forma totalmente diferente. A subjetividade, doravante capaz de apropriar a diferença para si, agora aparece como o que realmente é: a unidade sintética originária ligando suas determinações e, ao mesmo tempo, as colocando em uma forma sequencial. Quando a alma consegue idealizar o corpóreo, ela também ganha o poder de fazer de si própria uma 'unidade ideal e simples', ou seja, ser apenas consigo mesma. Esta substância ideal, diz Hegel, 'não é ainda um Self', mas é a possibilidade do Self. Como uma síntese de espírito e natureza, abre-se para o sujeito o horizonte no qual isso vai progredir - o horizonte da Bildung, da cultura, do desenvolvimento. Isso libera o sujeito dos obstáculos e das limitações daquele estado onde a natureza é ainda muito intensamente influente. Com o 'ato puro de intuição' o sujeito é agora aberto a possibilidade de 'ver (o que é) que vem' (idem, p. 38).

\section{Considerações finais}

A retomada do percurso argumentativo de Malabou (ibidem) nãoteve outro propósito senão o de fornecer algumas pistas que nos interessou desdobrar à luz da proatividade das câmeras inteligentes: 1) que as estruturas de antecipação são históricas; 2) que a plasticidade opera a atribuição e a recepção de forma e; 3) que o hábito produz uma mutação no regime de temporalidade natural e constitui o solo a partir do qual o self passa a poder voir venir. Desdobramos a primeira pista no curso da apresentação da tese de Malabou. A segunda e a terceira, entretanto, ainda precisam ser exploradas.

Quando projetada sobre nossa problematização das câmeras inteligentes, a ambivalência da operação plástica de atribuição e recepção de forma apresenta alguns desencaixes interessantes. Antes de explorá-los, é importante explicitar que a leitura que estamos empreendendo de dispositivos técnicos a partir de uma teoria da subjetividade repousa sobre a hipótese de que, através de processos de delegação, as máquinas inteligentes passam a ter a plasticidade como parte de seu programa, de onde proviria parte desta noção de inteligência. Dito isto, perguntamos: qual é o papel das câmeras inteligentes no processo de atribuição de forma ao mundo? Tomando emprestado o sistema filosófico hegeliano, via Malabou, podemos dizer que é interferindo, como um hábito, nos encontros entre substancialidade e acidentalidade, na tentativa de ver (o que é) que vem.

A novidade de tais dispositivos, aquilo que permite chamá-los de inteligentes é, além da correspondência e ultrapassagem da cognição humana na execução de certas tarefas, uma certa plasticidade do algoritmo. Algoritmos como os que operam no sistema de anúncios do Google ou aquele ficcionalizado no filme de Spike Jonze, Her (2013), são emblemas desta plasticidade, desta possibilidade de ação inscrita numa temporalidade que, no presente, articula passado e futuro, buscando apreender Kairós em todas as suas apressadas aparições. 
A despeito das limitações destes sistemas na concreção de tal projeto, sempre tematizadas pelos desenvolvedores como superáveis através de investimentos em pesquisa, gostaria de deslocar o problema de um questionamento da noção de inteligência como traço inerente à condição humana, para a condição ocupada por tais aparelhos, de próteses da capacidade humana de dar forma ao mundo e voir venir. Aqui entra em ação o terceiro postulado que extraímos de Malabou: o papel atribuído ao hábito na resolução da problemática da consistência do self. A delegação às máquinas das operações plásticas pode ser lida a partir daquilo que pensaremos como uma crise nos planos social, político, cultural e ambiental, que estaria desarticulando os processos de repetição capazes de forjar o hábito como segunda natureza.

Uma série de processos históricos e ambientais tem abalado profundamente os graus de certeza dos sujeitos em relação à permanência do mundo. Numa escala pessoal, podemos apontar os imperativos de flexibilização no âmbito do trabalho e aquilo que Sennett (2004) identificou como a corrosão do caráter, bem como a perda de lastro das relações pessoais, através do que Bauman (2004) chamou de amor líquido, como implicando uma dificuldade de ordem narrativa, ou seja, uma dificuldade em acolher o desenrolar temporal da experiência de estar no mundo como sendo dotada de um sentido e de uma correspondência entre as ações e seus efeitos. A este cenário, soma-se uma crise ambiental, com a crescente imprevisibilidade de eventos naturais catastróficos. Neste contexto, a experiência subjetiva do tempo tende a perder sua consistência e, em vez da memória, de pouca serventia quando o mundo é vivido como caos e eventos desconexos e agora delegada aos computadores, o esquecimento torna-se um imperativo, sob a perversa noção de flexibilidade (FERRAZ, 2010).

Sem que essa espessura de temporalidade seja vivida subjetivamente, o hábito não encontra condições de, através da repetição, cristalizar-se. Essa crise na atribuição e recepção de forma que perpassa a história do sujeito, configurando diferentes lógicas organizadoras das estruturas de antecipação, parece estar passando por uma nova inflexão. As câmeras inteligentes podem ser indicadores privilegiados do estado desta crise.

Icaro Ferraz Vidal Junior é mestre pela UFRJ e doutorando no Erasmus Mundus Joint Doctorate: Cultural Studies in Literary Interzones nas Università degli Studi di Bergamo e Université de Perpignan Via Domitia.

vidal.icaro@gmail.com 


\section{Referências}

BARTHES, R. La chambre claire: note sur la photographie. Paris: Gallimard, 2006.

BAUMAN, Z. Amor líquido. Rio de Janeiro: Jorge Zahar, 2004.

BELBACHIR, A. N. (Org.). Smart cameras. Nova lorque: Springer, 2010.

; GÖBEL, P. M. Smart cameras: a historical evolution. In: BELBACHIR, A. N. (Org.). Smart cameras. New York: Springer, 2010, p. 3-18.

BEZERRA JR., B. O ocaso da interioridade e suas repercussões sobre a clínica. In: PLASTINO, C. A. (org.). Transgressões. Rio de Janeiro: Contra Capa Livraria, 2002, p. 229-238.

BRUNO, F. Contramanual para câmeras inteligentes: vigilância, tecnologia e percepção. Galáxia (São Paulo, Online), n. 24, 2012, p. 47-63.

. Máquinas de ver, modos de ser: vigilância, tecnologia e subjetividade. Porto Alegre: Sulina, 2013.

CRARY, J. Techniques of the observer: on vision and modernity in the nineteenth century. Cambridge: MIT Press, 1992.

CUTTINGG-EDGE advance in CCTV software earns industry acclaim. Kingston University News (site). 22 de Junho de 2012. Disponível em: <http://www.kingston.ac.uk/news/article/609/22-jun2012-cuttingedge-advance-in-cctv-software-earns-industry-acclaim/>. Acesso em 13 ago. 2015.

EHRENBERG, A. Le culte de la performance. Paris: Hachette Littératures, 1991.

FAROCKI, H. Phantom Images. Public, Number 29: Localities. Toronto, 2004, p. 12-24.

FERRAZ, M. C. F. Homo deletabilis: corpo, percepção, esquecimento do século XIX ao XXI. Rio de Janeiro: Garamond, 2010.

FOUCAULT, M. História da sexualidade I: a vontade de saber. Rio de Janeiro: Edições Graal, 1988.

O nascimento da clínica. Rio de Janeiro: Forense Universitária, 2006.

Vigiar e punir: nascimento da prisão. Petrópolis: Vozes, 1997.

GÓMEZ-í̃̃IGUEZ, C. et alii. Análisis conceptual del término vigilancia desde principios del S. XX hasta la actualidad: uma perspectiva histórica. Revista de historia de la psicologia. Vol. 20, no 3-4, 1999, pp. 415-428.

HEGEL, G. W. F.. Aesthetics. Lectures on fine art. Oxford: Clarendon Press, 1975.

HEGEL, G. W. F.. Philosophy of mind [spirit]. Part 3 of the encyclopedia of the philosophical sciences (1830). Oxford: Clarendon Press, 1971.

MALABOU, C. The future of Hegel: plasticity, temporality and dialectic. New York: Routledge, 2005.

SENNETT, R. A corrosão do caráter: consequências pessoais do trabalho no novo capitalismo. Rio de Janeiro: Editora Record, 2004.

O declínio do homem público: tiranias da intimidade. São Paulo: Companhia das Letras, 1999.

SEPPALA, T. J. Tokyo cab company's backseat cams notice forgotten gear if you don't. Engadget (site). 10 de setembro de 2013. Disponível em: <http://www.engadget.com/2013/09/10/tokyo-cabcameras/>. Acessado em 13 ago. 2015.

SIBILIA, P. O show do eu: a intimidade como espetáculo. Rio de Janeiro: Nova Fronteira, 2008. 